\title{
Generation of Highly Vibrationally Excited CO in Sequential Photodissociation of Iron Carbonyl Complexes
}

Keigo Nagamori,${ }^{\dagger}$ Misato Haze ${ }^{\dagger}$ Hiroyuki Nakata,${ }^{\dagger}$ Oliver Zingsheim,${ }^{\dagger}$ Katsuyoshi Yamasaki, ${ }^{\dagger}$ and Hiroshi Kohguchi ${ }^{\dagger},{ }^{*}$

$\dagger$ Department of Chemistry, Graduate School of Advanced Science and Engineering, Hiroshima University, Kagamiyama 1-3-1, Higashi-Hiroshima, Hiroshima 739-8526 Hiroshima, Japan

$\ddagger$ I. Physikalisches Institut, Universität zu Köln, Zülpicher Strasse 77, 50937 Köln, Germany

\section{Supporting Information}




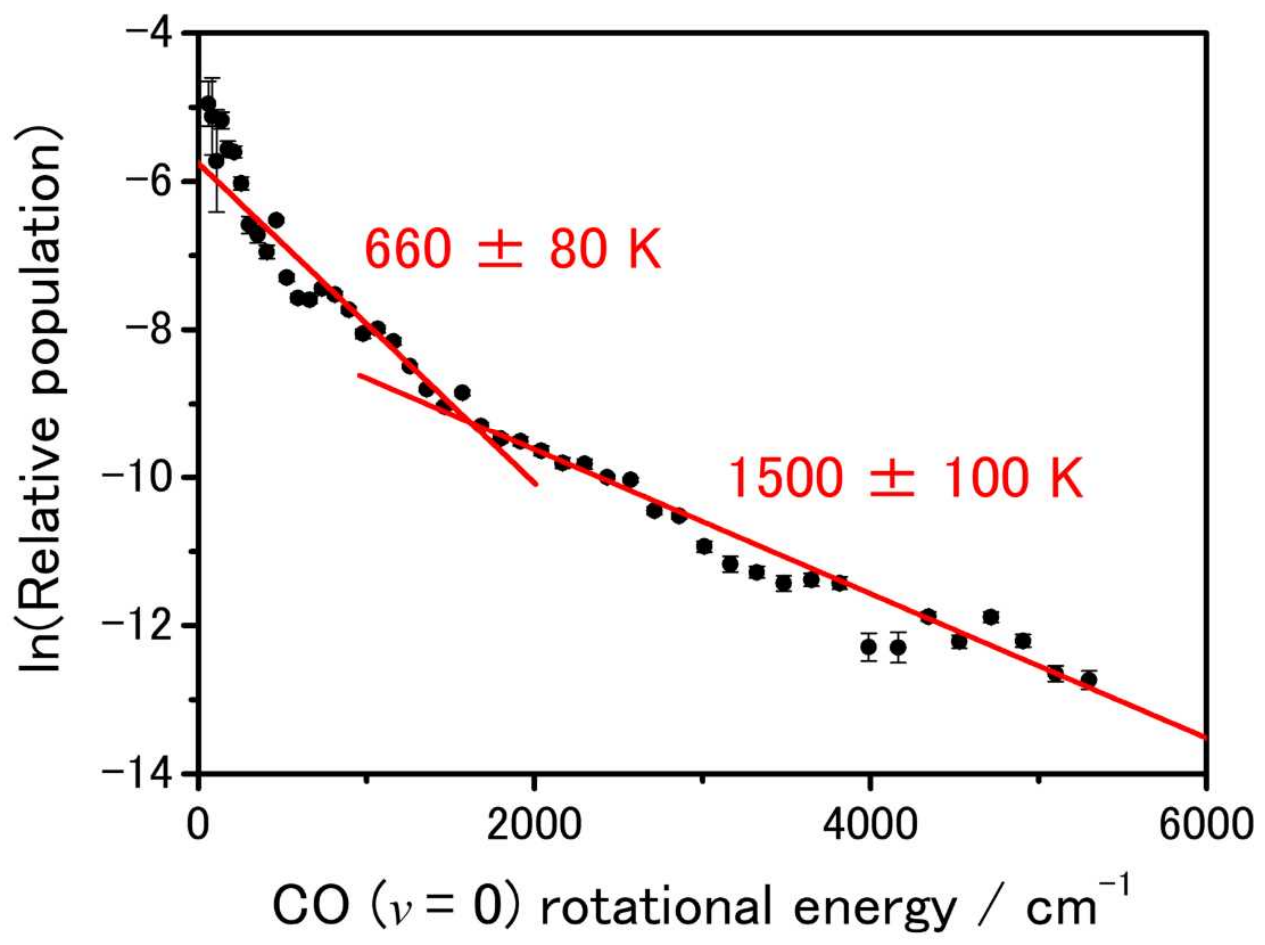

Figure S1 Boltzmann plot of the rotational state distribution of $\mathrm{CO}(v=0)$ fragment. The rotational state population are obtained by correcting the rotational line intensities of the $0-0$ band with the Hönl-London factor.

Although the population analysis remains qualitative partly because of the short lifetime of the $\widetilde{\mathrm{B}}{ }^{1} \Sigma^{+}$state, the Boltzmann plot is similar to the previous results by Waller and Hepburn in that multiple temperature components are involved; the temperature components of the $\mathrm{CO}$ fragments varied with the photolysis wavelengths: $(1926 \mathrm{~K}, 1429 \mathrm{~K}$, and $427 \mathrm{~K})$ at $193 \mathrm{~nm}$ and $(1716 \mathrm{~K}, 1162$ $\mathrm{K}$, and $340 \mathrm{~K}$ ) at $248 \mathrm{~nm} .{ }^{1}$ Two temperatures, $660 \mathrm{~K}$ for the lower rotational states $\left(E_{\mathrm{rot}}<1800 \mathrm{~cm}^{-1}\right)$ and $1400 \mathrm{~K}$ for the higher rotational states $\left(E_{\mathrm{rot}}>1800 \mathrm{~cm}^{-1}\right)$, are well fitted to the present plot at the photolysis wavelength of $230 \mathrm{~nm}$. The result of the rotational state distribution of $\mathrm{CO}$ based on the REMPI detection scheme is consistent with the previous data obtained by VUV-LIF spectroscopy. 


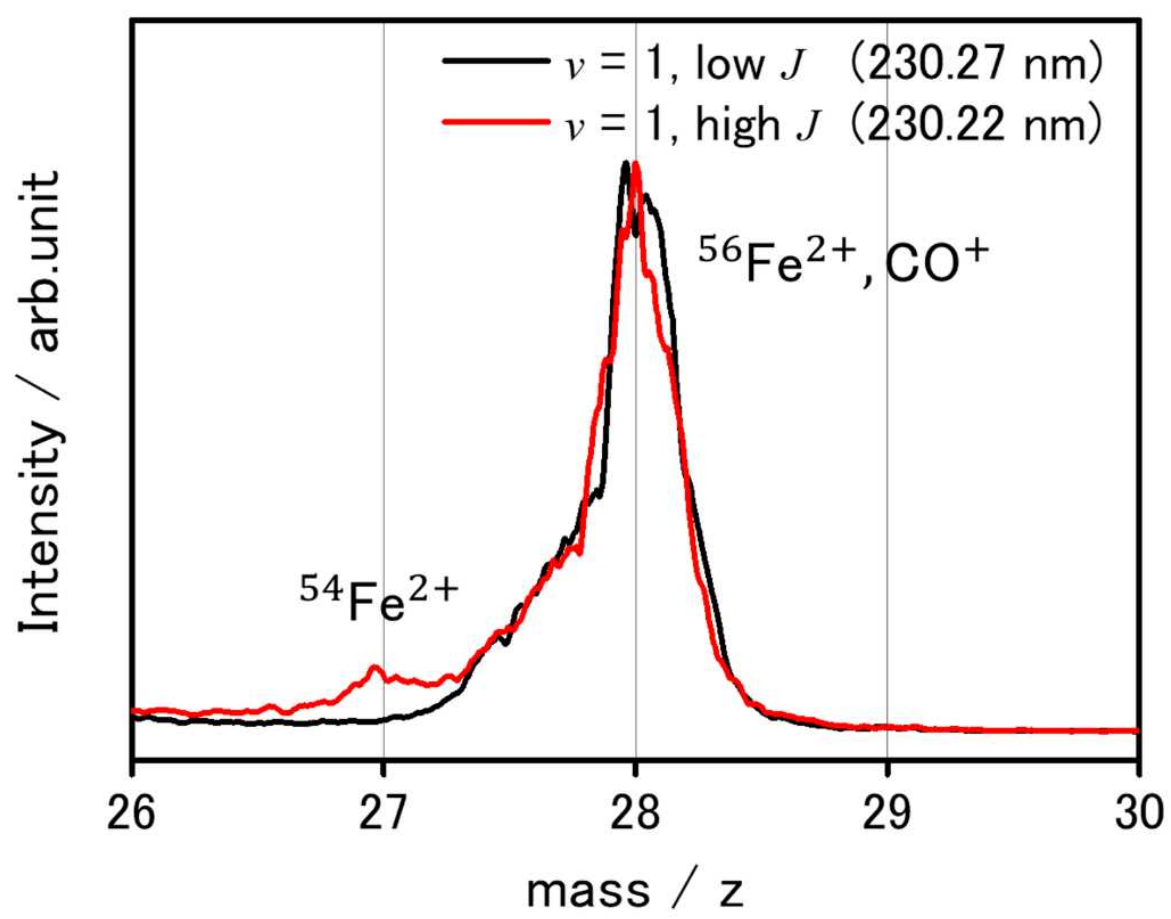

Figure S2 TOF-mass spectra of the photofragments in the $\mathrm{Fe}(\mathrm{CO})_{5}$ photodissociation at the photolysis wavelengths of $230.27 \mathrm{~nm}$ (black curve) and $230.22 \mathrm{~nm}$ (red curve). The wavelengths of $230.27 \mathrm{~nm}$ and $230.22 \mathrm{~nm}$ correspond to the low rotational and high rotational transition regions of the $[2+1]$ REMPI spectra via the $\widetilde{\mathrm{B}}^{1} \Sigma^{+}, v^{\prime}=1-\widetilde{X}^{1} \Sigma^{+}, v^{\prime \prime}=1$ band, respectively.

Ionization at $230.22 \mathrm{~nm}$ yielded both peaks for $m / z=28\left(\mathrm{CO}^{+}\right.$and $\left.{ }^{56} \mathrm{Fe}^{2+}\right)$ and at $m / z=27$ $\left({ }^{54} \mathrm{Fe}^{2+}\right)$. The relative intensity between $m / z=28$ and 27 was explained as the natural abundance of ${ }^{56} \mathrm{Fe}(91.8 \%)$ and ${ }^{54} \mathrm{Fe}(5.8 \%)$ isotopologues, indicating the resonant ionization of $\mathrm{Fe}$ at $230.22 \mathrm{~nm}$. The peak at $m / z=27$ disappeared at $230.27 \mathrm{~nm}$, which is off-resonant for Fe but on-resonant for CO. Thus, the prominent peak in the high $J$ region of the REMPI spectra measured for $m / z=28$ (Figure 2, inset) is assigned to $\mathrm{Fe}^{2+}$. 


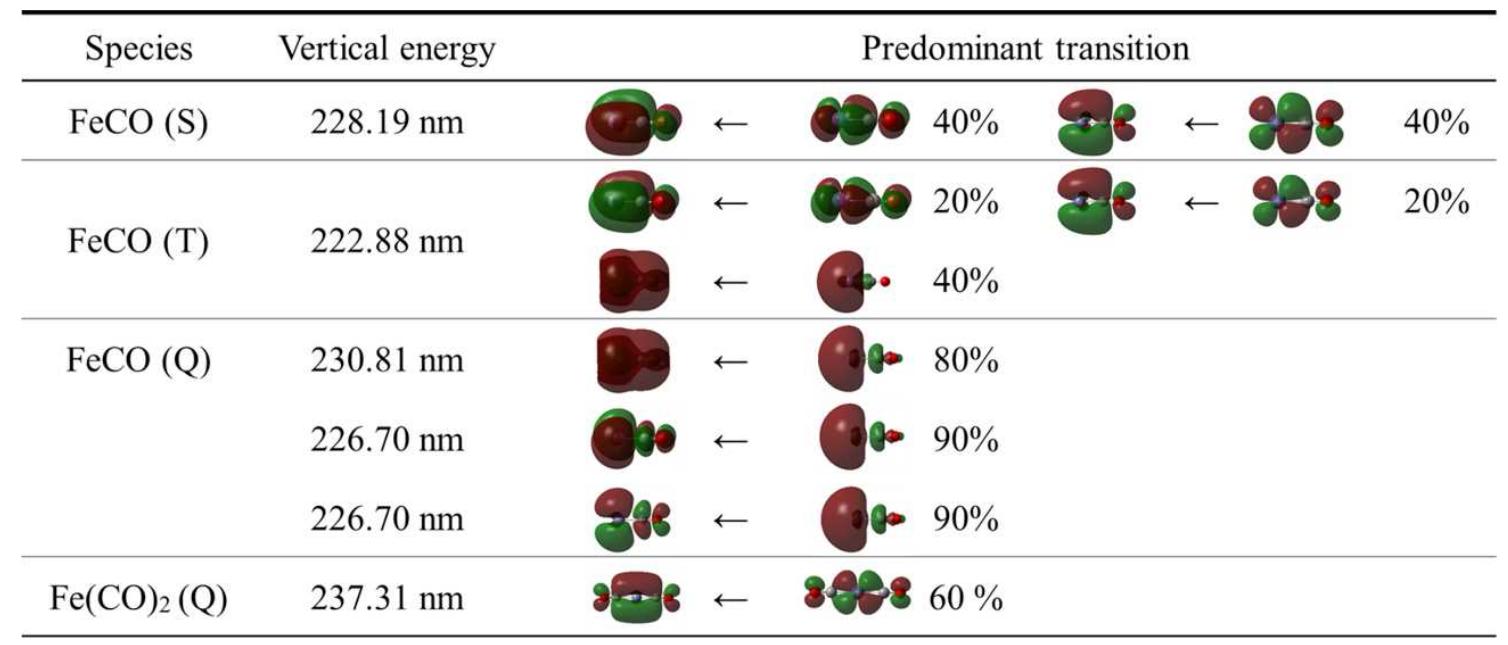

Figure $\mathrm{S} 3 \quad$ Molecular orbitals of $\mathrm{FeCO}$ and $\mathrm{Fe}(\mathrm{CO})_{2}$ relevant to ultraviolet photoabsorption. Fraction (\%) of the dominant molecular orbitals and the vertical energy (in $\mathrm{nm}$ ) are shown for the electronic transitions from the lowest electronic state with each spin multiplicity (S: singlet, T: triplet, Q: quintet).

The excited states of the singlet $\mathrm{FeCO}$ are largely contributed from the $4 \mathrm{p}$ orbital of Fe. Although anti-bonding character of the $\mathrm{Fe}-\mathrm{C}$ bond is not ascertained by the nodal patterns of the molecular orbitals, dissociation to $\mathrm{Fe}+\mathrm{CO}(v=15)$ in the photoexcited $\mathrm{FeCO}(\mathrm{S})$ state can be energetically supported. 
(a)
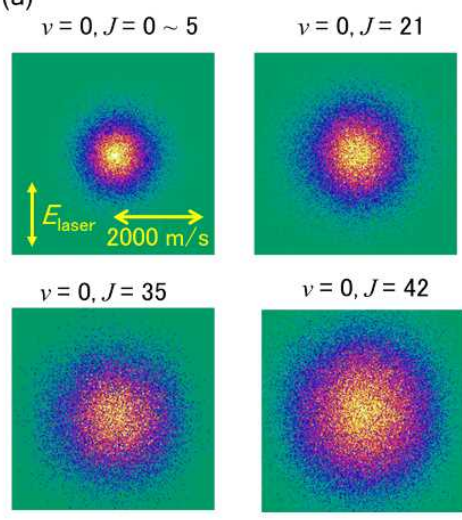

$v=0, J=42$

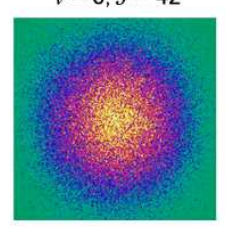

$v=0, J=25$

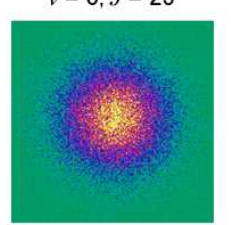

$v=11$

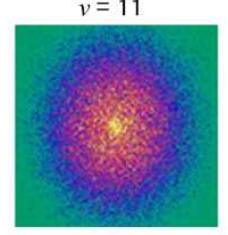

(b)

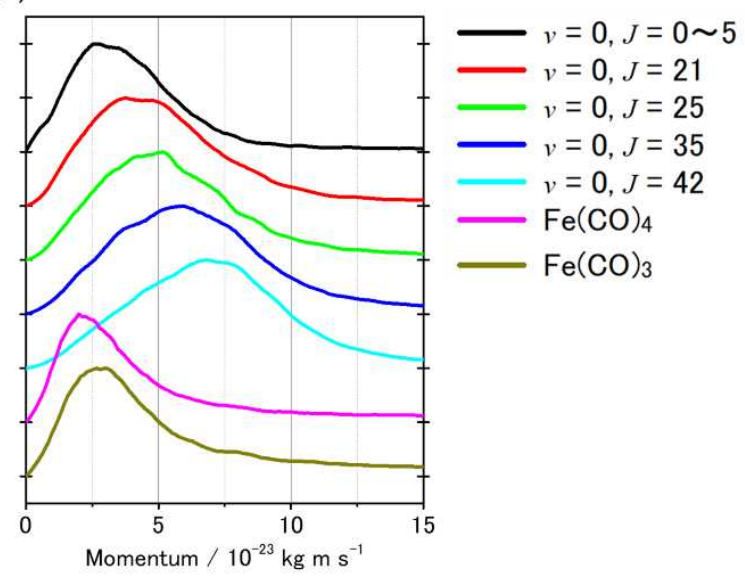

Figure S4

(a) Rotationally state-resolved scattering images of the CO photofragments in the $v=0$ states. The image data of the CO fragment in the $v=11$ state is shown as an example of the scattering images of the highly vibrationally excited states. (b) Linear momentum distributions of the CO photofragments in the $v=0$ state obtained from the state-resolved scattering distributions.

The CO photofragments in the low vibrational states are contributed from several photolytic processes of $\mathrm{Fe}(\mathrm{CO})_{n=1-5}$. Although individual fragmentations remain unresolved in the observed results, state-dependence of the ion-imaging results indicates a possible generation origin of the $\mathrm{CO}$ fragments in the low rotational states. The released momentum distributions of the low- $J$ CO fragments showed relatively large overlap with those of $\mathrm{Fe}(\mathrm{CO})_{3}$ and $\mathrm{Fe}(\mathrm{CO})_{4}$ (Figure $\mathrm{S} 4 \mathrm{~b}$ ), both of which are widely accepted as the major products in the first photodissociation of $\mathrm{Fe}(\mathrm{CO})_{5}$ in previous studies. ${ }^{2-4}$ The results of the momentum matching imply that the first photodissociation of $\mathrm{Fe}(\mathrm{CO})_{5}$ partly generates the $\mathrm{CO}$ product with low rotational excitation. Decrease of the degree of the momentum matching to $\mathrm{Fe}(\mathrm{CO})_{4}$ and $\mathrm{Fe}(\mathrm{CO})_{3}$ as the higher internal energy is regarded as a result of increasing contribution of the secondary photodissociation of the $\mathrm{Fe}(\mathrm{CO})_{n<4}$ intermediates $\left(\mathrm{Fe}(\mathrm{CO})_{n<4}\right.$ $\left.+\mathrm{h} v \rightarrow \mathrm{Fe}(\mathrm{CO})_{n-1}+\mathrm{CO}\right)$, which could be internally excited at the first photodissociation of $\mathrm{Fe}(\mathrm{CO})_{5}$ in the same laser pulse. We decomposed the rotational state distributions (Figure S1) into two temperature components. Examination of both the final state distribution and the released momentum distribution suggests that the lower temperature component is possibly originated from the first photodissociation of the $\mathrm{Fe}(\mathrm{CO})_{5}$ parent. 


\section{REFERENCES}

1. Waller, I. M.; Hepburn, J. W. State-Resolved Photofragmentation Dynamics of $\mathrm{Fe}(\mathrm{CO})_{5}$ at $193,248,266$, and $351 \mathrm{~nm}$. J. Chem. Phys. 1988, 88, 6658-6669.

2. Trushin, S. A.; Fuss, W.; Kompa, K. L.; Schmid, W. E. Femtosecond Dynamics of $\mathrm{Fe}(\mathrm{CO})_{5}$ Photodissociation at $267 \mathrm{~nm}$ Studied by Transient Ionization. J. Phys. Chem. A 2000, 104, 1997-2006.

3. Wernet, P.; Leitner, T.; Josefsson, I.; Mazza, T.; Miedema, P. S.; Schroder, H.; Beye, M.; Kunnus, K.; Schreck, S.; Radcliffe, P.; Dusterer, S.; Meyer, M.; Odelius, M.; Fohlisch, A. Direct evidence for sequential dissociation of gas-phase $\mathrm{Fe}(\mathrm{CO})_{5}$ via a singlet pathway upon excitation at 266 nm. J. Chem. Phys. 2017, 146, 211103.

4. Cole-Filipiak, N. C.; Tross, J.; Schrader, P.; McCaslin, L. M.; Ramasesha, K. Ultraviolet photodissociation of gas-phase iron pentacarbonyl probed with ultrafast infrared spectroscopy. J. Chem. Phys. 2021, 154, 134308. 